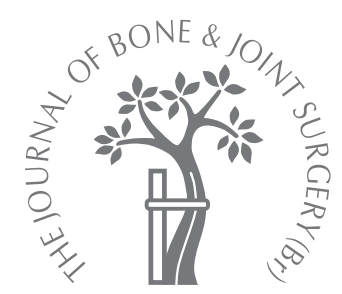

\title{
Reconstruction with callus distraction for nonunion with bone loss and leg shortening caused by suppurative osteomyelitis of the femur
}

X. Zhang,
T. Liu,
Z. Li,
W. Peng

From Second

Xiangya Hospital,

Hunan, People's

Republic of China
X. Zhang, MD, Orthopaedic Surgeon, Professor

T. Liu, MD, Orthopaedic

Surgeon

Z. Li, MD, Orthopaedic

Surgeon

W. Peng, MD, Orthopaedic

Surgeon

Department of Orthopaedics

Second Xiangya Hospital,

Center South University,

Changsha, Hunan 410011

People's Republic of China.

Correspondence should be sent to $\mathrm{Dr}$ T. Liu; e-mail: liutang1204@126.com

(C)2007 British Editorial Society of Bone and Joint Surgery doi:10.1302/0301-620X.89B11. $19239 \$ 2.00$

$J$ Bone Joint Surg $[\mathrm{Br}]$

2007;89-B:1509-14.
Received 26 January 2007;

Accepted after revision 23 May

2007

\begin{abstract}
We present a retrospective study of 27 patients treated by callus distraction using a unilateral external fixator of our own design for nonunion with bone loss and shortening of the femur caused by suppurative osteomyelitis. The unilateral external fixator was used either alone or in combination with an intramedullary nail. The mean age of the patients was 13.6 years ( 8 to 18 ). The fixator was used alone in 13 patients and with an intramedullary nail in 14. The bone results at a mean follow-up of 88 months (37 to 144) were excellent in 16 patients and good in 11.

The functional results were excellent in 18 patients and good in nine. However, four patients still had draining sinuses at the latest follow-up. A residual deformity greater than $7^{\circ}$ was present in seven femora, but this did not adversely affect function or require further treatment.
\end{abstract}

In the past, bone loss as a result of infection and trauma has been treated with autogenous bone grafts, vascularised bone grafts, allografts and artificial bone substitutes. ${ }^{1}$ More recently callus distraction has become popular for the treatment of leg-length discrepancy, deformity, nonunion and bone loss. ${ }^{2-13}$ We report the results of 27 patients suffering from nonunion, bone loss and leg shortening following osteomyelitis who were treated by callus distraction.

\section{Patients and Methods}

We undertook a retrospective study of 27 patients treated in our unit between October 1994 and January 2004 for nonunion of the femur with bone loss following osteomyelitis. Callus distraction with a unilateral fixator alone or in combination with an intramedullary nail was used in all patients. The mean age of the patients was 13.6 years ( 8 to 18 ). In 25 of the 27 patients (93\%) bone grafting had been previously undertaken using autogenous fibula, iliac bone, or demineralised bone, three to five years after control of the osteomyelitis, and had failed. According to Paley's classification of nonunion, ${ }^{14}$ all patients were type B3 (nonunion with bone loss and leg shortening). In 24 patients $(89 \%)$, the site of nonunion was in the femoral shaft. In the remaining three $(11 \%)$ it was in the distal femur and was associated with a stiff knee joint. No patient had symptoms or signs of active osteomyelitis. All the laboratory parameters of infection, such as the C-reactive protein level, erythrocyte sedimentation rate, white blood-cell count and differential, were normal. The mean amount of bone loss was $2.0 \mathrm{~cm}$ (1.0 to 3.5$)$ as measured on plain radiography. The mean leg-length discrepancy was $7.8 \mathrm{~cm} \mathrm{(2.7} \mathrm{to} 16.5)$.

External fixator. A unilateral external fixator (Third Medical Instrument Company, Wujin, China) (Fig. 1) was used for callus distraction in all patients. It has two screw rods and two link rails and is a stable rectangular plane fixator which is connected to the bone by the link rails and threaded pins. When the bone is lengthened or compressed the press boards (used to make the fixator more stable) are removed and an S-needle is used to rotate the screw rods through a modulating hole in the middle of the rod. The three-segment fixator, allows distraction in one segment of the bone and compression at another at the same time. Operative technique. Pre-operative radiographs were taken in the sagittal and coronal planes to assess the nonunion, to determine the planes of the osteotomies and the length and diameter of the intramedullary nails if required. The external fixator was used alone in 13 patients (group A) and combined with an intramedullary nail (Fig. 2) in a further 14 (group B).

Callus distraction with external fixation (group A). The patient was supine on a radiolucent table with a pillow under the ipsilateral buttock. The sclerotic bone ends were not 


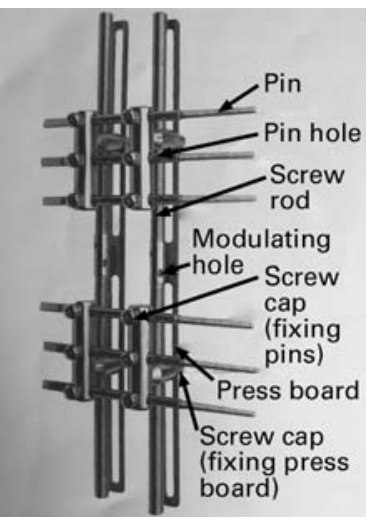

Fig. 1a
Fig. 1b

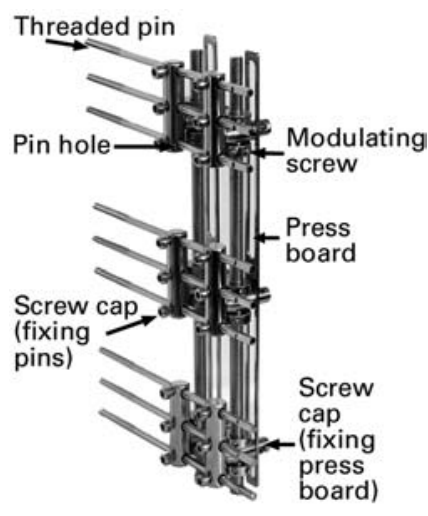

Photographs showing a) a two-segment unilateral external fixator which can be used either to compress or to elongate. The link rail is composed of pins and the pin fixator, and b) a three-segment unlateral external fixator which can compress one bone segment and elongate the other.

removed. Under image intensifier control one or two proximal pins, $4.5 \mathrm{~mm}$ diameter, were inserted at the level of the lesser trochanter at right-angles to the anatomical axis of the femur. Next, one or two diaphyseal pins, $4.5 \mathrm{~mm}$ diameter, were inserted approximately $2 \mathrm{~cm}$ to $3 \mathrm{~cm}$ below the level which had been selected for the osteotomy. One or two distal pins, $4.5 \mathrm{~mm}$ diameter, were inserted at the level of the superior pole of the patella if necessary. All these pins should be inserted in the same plane. The femoral shaft was exposed subperiosteally and a transverse osteotomy made at the pre-selected level. The periosteum was sutured and the wound closed with a drainage tube. The external fixator was attached with a $2 \mathrm{~cm}$ gap between it and the thigh, to allow for swelling.

Callus distraction over an intramedullary nail (group B). Antegrade reaming of the femur over an intramedullary guidewire was carried out to a diameter $1.5 \mathrm{~mm}$ larger than that of the selected intramedullary nail. The nail was then inserted temporarily. Under image intensification, one or two proximal pins, $4.5 \mathrm{~mm}$ diameter, were inserted approximately $2 \mathrm{~cm}$ to $3 \mathrm{~cm}$ above the pre-selected osteotomy site and one or two pins, $4.5 \mathrm{~mm}$ diameter, were inserted approximately $2 \mathrm{~cm}$ to $3 \mathrm{~cm}$ distal to it. All the pins were positioned beyond the nail. The intramedullary nail was then removed and a transverse osteotomy performed subperiosteally. The nail was then reinserted and secured distally with a locking screw. The excess length of the nail was left in the soft tissues proximally. The body of the unilateral frame was then applied. Care should be taken to avoid contact between the pins of the external fixator and the intramedullary nail, and the distal locking screw should be placed $2 \mathrm{~cm}$ to $3 \mathrm{~cm}$ away from the pins. ${ }^{10,15}$

All patients were given a seven-day course of intravenous broad-spectrum antibiotics post-operatively. Partial weightbearing and physiotherapy were encouraged from the second post-operative day. Distraction was started five to seven days after the operation at a rate of $1.0 \mathrm{~mm}$ per $36 \mathrm{hrs}$ in four increments of $0.25 \mathrm{~mm}$. When the regenerate bone length had reached approximately $6.0 \mathrm{~cm}$, the rate of distraction was reduced to $1.0 \mathrm{~mm}$ every $48 \mathrm{hrs}$ in four increments of $0.25 \mathrm{~mm}$. Clinical and radiological examination was carried out every 15 days to assess new bone formation

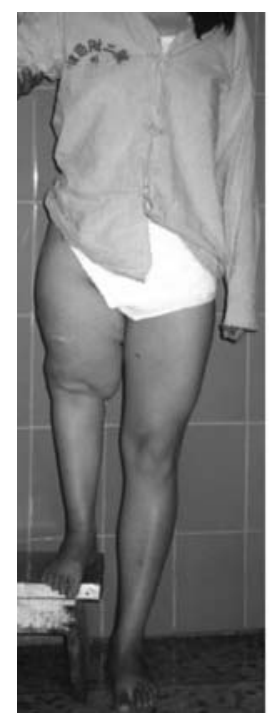

Fig. $2 a$

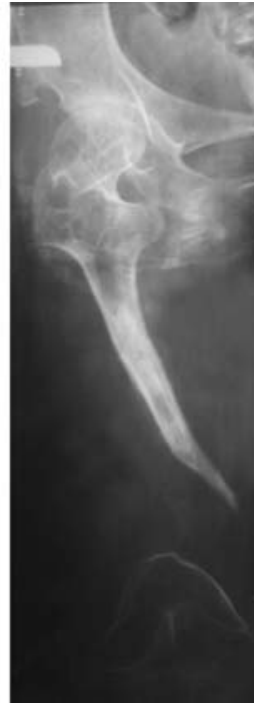

Fig. 2b

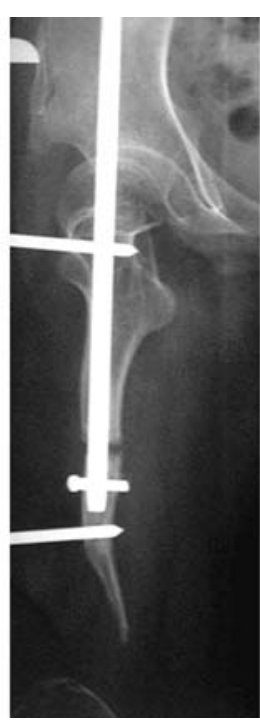

Fig. 2c

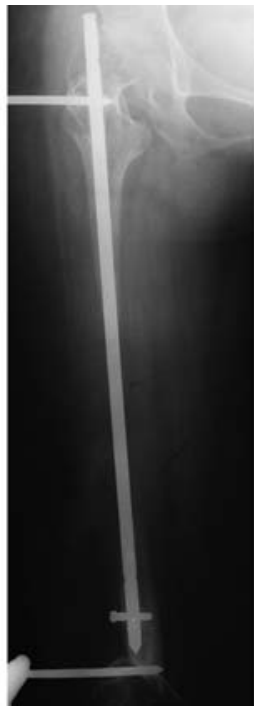

Fig. 2d

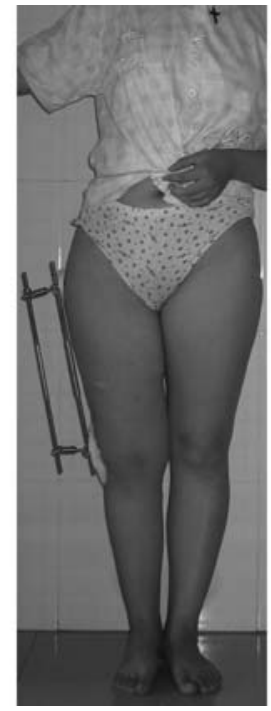

Fig. $2 e$

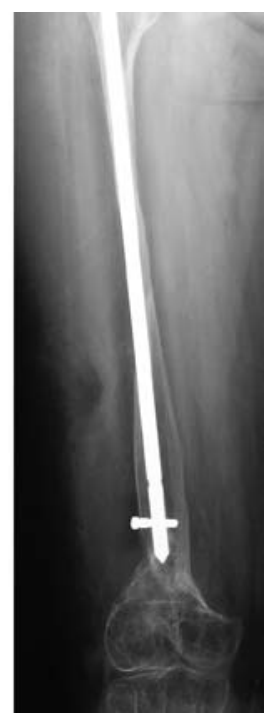

Fig. $2 f$

a) Photograph of a four-year-old girl with $16.5 \mathrm{~cm}$ of leg shortening, b) pre-operative anteroposterior radiograph of her femur, c) after application of the unilateral fixator osteotomy and intramedullary nail, d) showing bone segment in contact, e) clinical photograph two years after callus distraction with the external fixator in place, and f) anteroposterior radiograph after removal of the fixator at two years. 
Table I. Comparison of the treatment groups

\begin{tabular}{|c|c|c|c|}
\hline Category group & Group A & Group B & p-value \\
\hline Mean external fixator index (days/cm) & $41.9 \quad(37.8$ to 48.4$)$ & (14.9 to 24.3$)$ & $<0.001$ \\
\hline Mean radiological consolidation index (days/cm) & $41.9 \quad(37.8$ to 48.4$)$ & (30.7 to 51.6$)$ & 0.027 \\
\hline Rate of complication & 2.08 (27 of 13$)$ & 1.5 (21 of 14$)$ & - \\
\hline Rate of pin-track infection & 0.85 (11 of 13$)$ & $0.500(7$ of 14$)$ & - \\
\hline Rate of complication (excluding pin-track infection) & $1.23(16$ of 13$)$ & $1.00 \quad(4$ of 14$)$ & - \\
\hline Mean pre-operative knee flexion ( ${ }^{\circ}$ ) & 98.2 & (excluding the 3 rigidity knees) & - \\
\hline Mean post-operative knee flexion $\left({ }^{\circ}\right)$ & 88.3 & 86.4 & - \\
\hline Flexion regained after treatment $(\%)$ & $0.90\left(88^{\circ}\right.$ of $\left.98.2^{\circ}\right)$ & $0.91\left(86.4^{\circ}\right.$ of $\left.94.7^{\circ}\right)$ & 0.337 \\
\hline $\begin{array}{l}\text { Six months after the end of consolidation, rate of } \\
\text { knee restricted }>20^{\circ} \text { compared with pre-operatively }\end{array}$ & $0.55(7$ of 13$)$ & $0.36 \quad(5$ of 14$)$ & - \\
\hline
\end{tabular}

Table II. Results

\begin{tabular}{|c|c|c|c|c|c|}
\hline Case & Bone length achieved & $\begin{array}{l}\text { External fixator index } \\
\text { (days } / \mathrm{cm} \text { ) }\end{array}$ & $\begin{array}{l}\text { Consolidation index } \\
\text { (days } / \mathrm{cm} \text { ) }\end{array}$ & $\begin{array}{l}\text { Bone status at latest } \\
\text { follow-up }\end{array}$ & $\begin{array}{l}\text { Functional status at } \\
\text { latest follow-up }\end{array}$ \\
\hline 1 & 10.0 & 37.8 & 37.8 & Union (deformity), good & Excellent \\
\hline 2 & 11.5 & 38.8 & 38.8 & Union, excellent & Good \\
\hline 3 & 9.0 & 39.8 & 39.8 & Union, excellent & Excellent \\
\hline 4 & 12.5 & 39.6 & 39.6 & Union (deformity), good & Excellent \\
\hline 5 & 9.5 & 47.2 & 47.2 & Union, excellent & Good \\
\hline 6 & 12.5 & 45.3 & 45.3 & Union (infection), good & Excellent \\
\hline 7 & 12.7 & 40.7 & 40.7 & Union (deformity), good & Excellent \\
\hline 8 & 11.5 & 38.2 & 38.2 & Union, excellent & Excellent \\
\hline 9 & 6.0 & 41.6 & 41.6 & Union, excellent & Excellent \\
\hline 10 & 15.7 & 39.8 & 39.8 & Union (infection), good & Excellent \\
\hline 11 & 18.0 & 15.3 & 33.2 & Union, excellent & Excellent \\
\hline 12 & 16.8 & 15.8 & 31.8 & Union (deformity), good & Good \\
\hline 13 & 9.7 & 43.7 & - & Union (deformity), good & Good \\
\hline 14 & 7.5 & 43.4 & - & Union, excellent & Excellent \\
\hline 15 & 19.5 & 18.5 & 38.0 & Union, excellent & Good \\
\hline 16 & 12.8 & 18.1 & 36.9 & Union, excellent & Excellent \\
\hline 17 & 12.5 & 19.1 & 41.2 & Union, excellent & Good \\
\hline 18 & 7.0 & 23.4 & 39.5 & Union, excellent & Excellent \\
\hline 19 & 7.0 & 24.3 & 51.6 & Union, excellent & Good \\
\hline 20 & 14.5 & 18.7 & 37.8 & Union (infection), good & Excellent \\
\hline 21 & 15.5 & 17.6 & 32.4 & Union, excellent & Excellent \\
\hline 22 & 13.5 & 14.9 & 30.7 & Union (deformity), good & Good \\
\hline 23 & 8.5 & 17.2 & 35.0 & Union, excellent & Good \\
\hline 24 & 12.0 & 15.6 & 39.0 & Union, excellent & Excellent \\
\hline 25 & 8.5 & 20.4 & 39.6 & Union, excellent & Excellent \\
\hline 26 & 13.5 & 21.3 & 42.3 & Union (deformity), good & Excellent \\
\hline 27 & 6.0 & 48.4 & - & Union (infection), good & Excellent \\
\hline
\end{tabular}

and the pin sites. When the length of the regenerated bone was greater than $40 \%$ of the original limb length, the decision whether to stop or continue was taken depending on the state of the blood supply, sensation and movement in the limb. Once the decision had been taken to stop lengthening or the required length had been achieved, in group A the external fixator was removed when sufficient consolidation was obtained, i.e. when at least three of four cortices were observed to be united on anteroposterior (AP) and lateral radiographs, and in group $\mathrm{B}$, proximal locking screws were inserted into the nail and the fixator removed to facilitate unrestricted rehabilitation.

Statistical analysis. Statistical significance between the two groups was evaluated using Student's $t$-test. A p-value $<0.05$ was considered to be significant.

\section{Results}

The 27 patients were followed up for a mean of 88 months (37 to 144). The results are given in Tables I and II. The mean external fixation index was 41.9 days $/ \mathrm{cm}$ (37.8 to 48.4) in group A and 18.6 days/cm (14.9 to 24.3) in group B. The mean radiological consolidation was 41.8 days $/ \mathrm{cm}$ (37.8 to 48.4 ) in group A and 37.8 days/cm (30.7 to 51.6) in group $B$.

The results were divided into bone results and functional results. For bone results, four criteria were evaluated as recommended by Paley et al: ${ }^{15}$ union, infection, deformity and leg-length discrepancy. All patients achieved union, but four still had draining sinuses at the latest follow-up, and one of these four had a persistent deep infection. A residual deformity $>7^{\circ}$ was present in seven patients. No 


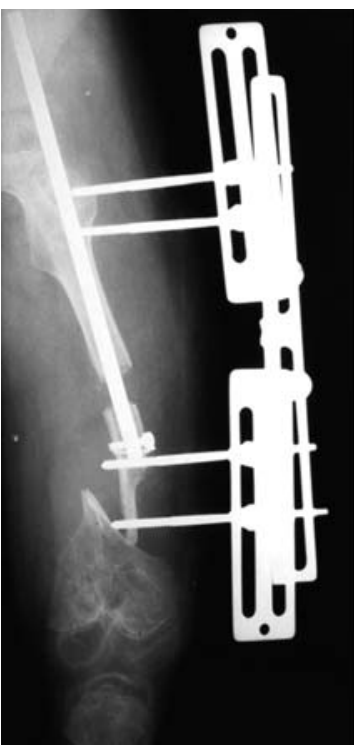

Fig. 3a

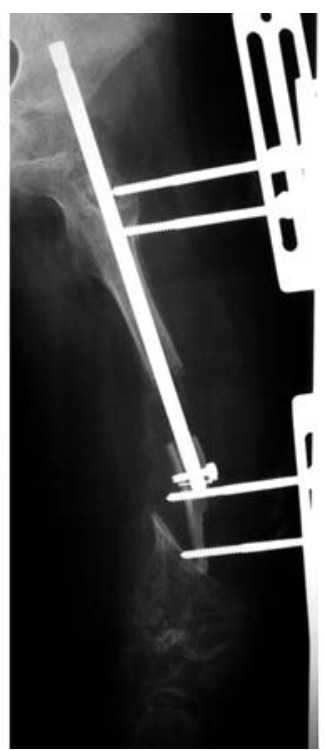

Fig. 3b

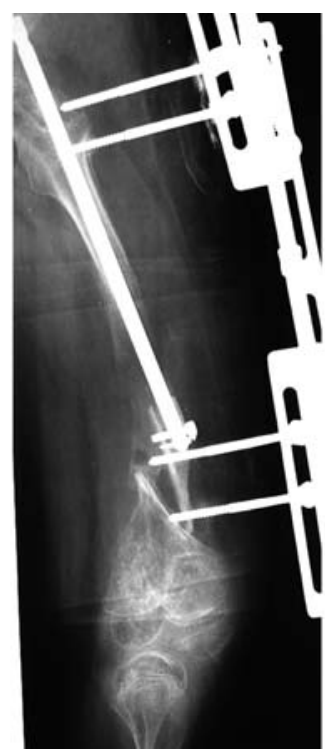

Fig. 3c

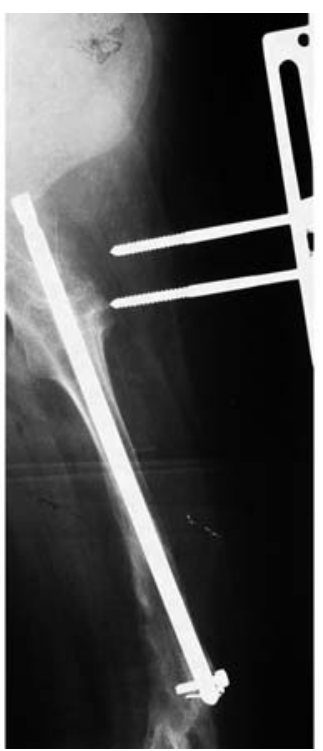

Fig. 3d

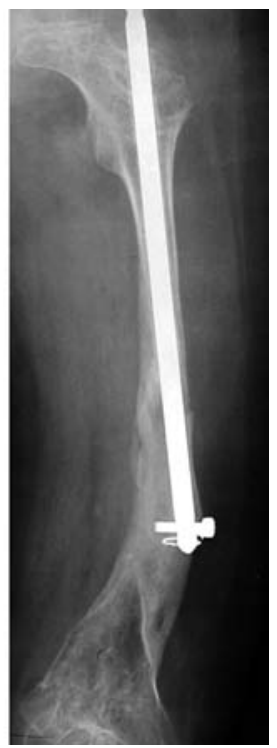

Fig. 3e

Anteroposterior radiographs showing a) callus distraction performed with a unilateral external fixator and intramedullary nail, b) and c) in the process of lengthening, obvious bone regeneration can be seen in the non-contact area at the docking site of the non-elongated bone segment, d) and e) showing that the proximal pins have pulled out of the femur.

patient had a residual leg-length inequality of $>2.5 \mathrm{~cm}$. An excellent bone result was one in which there was union, no infection, deformity $<7^{\circ}$, and leg-length discrepancy $<2.5 \mathrm{~cm}$. A good result was union, plus two of the other criteria; a fair result was union plus one of the other criteria; a poor result was nonunion or refracture, or none of the other criteria. Based on these criteria, 16 bone results were excellent, 11 good and none was fair or poor.

The functional results were based on six criteria recommended by Paley et al, ${ }^{15}$ range of movement of the knee, amount of lengthening achieved, gait, lateral distal femoral angle, pain, and ability to perform activities of daily living (ADL) or to work. All patients regained their ADL and, where appropriate returned to work. However, they all still had a limp. If the knee joint was stiff before treatment it remained so afterwards. Based on these criteria, 18 functional results were excellent, nine good and none was fair or poor.

Complications. These were reported as recommended by Paley. ${ }^{16}$ Superficial pin-track infections recurred in 16 of 27 limbs $(59 \%)$ and responded to oral or intravenous antibiotics. Movements of the knee joint were restricted by $20^{\circ}$ more than before operation in 12 patients (44\%). However, 11 improved with functional exercises and one required a manipulation under anaesthetic.

Severe pin-track infections were found in two patients $(7.4 \%)$ and one pin had to be removed. Deep infection was found in one patient in group B after successful lengthening. This was confirmed by culturing specimens taken when the nail was removed and was eradicated by reaming the medullary canal and the use of intravenous antibiotics. During distraction, pin loosening caused by osteoporosis occurred in four limbs, all of which were treated by repositioning of the pins. In one limb the proximal femoral pins slipped out of the femur and the external fixator was removed (Figs 3 and 4). Subluxation of the hip joint occurred in three patients with acetabular dysplasia prior to treatment. This was treated by traction, closed reduction and an acetabular shelf procedure. A residual deformity $>7^{\circ}$ was present in seven femora after removal of the fixator. However, no treatment was required for this as all the patients walked well without support.

There were no refractures, neurological or vascular injuries. There were no problems with avascular necrosis of the femoral head in group B, where an intramedullary nail was used.

\section{Discussion}

Treatment of nonunion with bone loss and leg shortening caused by suppurative osteomyelitis during childhood has rarely been reported.

For many years, the most common treatment has been bone grafting to fill the defect. Several techniques have been described, including autogenous bone graft, allograft bone, and synthetic bone substitute, either alone or in conjunction with internal fixation. ${ }^{1,17}$ The major disadvantages are that healthy tissue may be sacrificed, as in autogenous bone grafts, the grafted bone may be absorbed and full weight- 


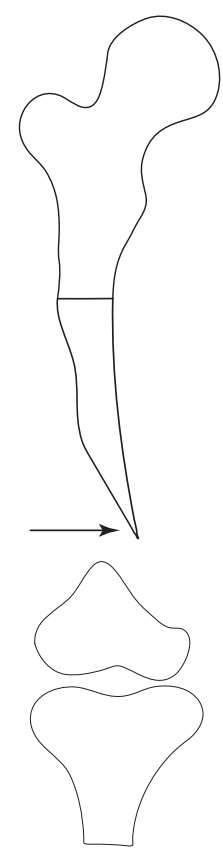

Fig. $4 a$

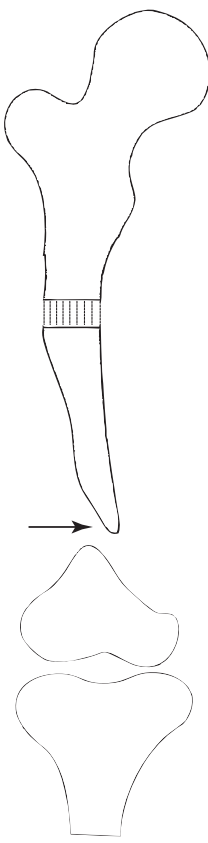

Fig. 4b

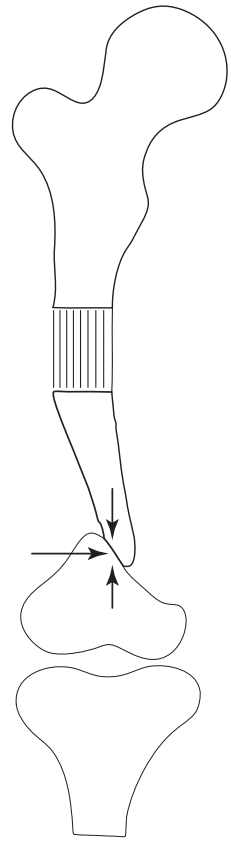

Fig. 4c

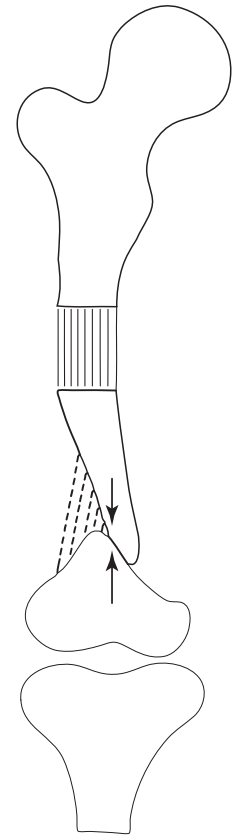

Fig. 4d

Diagram showing a) nonunion accompanied by bone loss and leg shortening due to suppurative osteomyelitis, b) post callus distraction, c) bone segments contacted and d) bone regeneration in the non-contact area at the docking site of the non-elongated bone segment (bone absortion is indicated by the arrows and regeneration by the dashed area).

bearing is usually delayed until the graft shows signs of hypertrophy.

In 1987, De Bastiani et $\mathrm{al}^{3}$ introduced the concept of callus distraction (callotasis). This technique has several advantages ${ }^{2,6,11,18-20}$ and can be used to treat large bony deficiencies. ${ }^{6}$ In this study, good outcomes were obtained with leg lengthening ranging between $6 \mathrm{~cm}$ and $19.5 \mathrm{~cm}$. We did not expose the docking site to remove sclerotic bone and scar tissue. During lengthening, the defect was gradually closed at the same rate as the movement of the segment of bone between the osteotomy and the defect. After the defect had been closed, distraction was continued to correct leg-length discrepancy ${ }^{12}$ and compression was applied to the docking site to facilitate union.

Currently, a distraction rate of $0.25 \mathrm{~mm}$ every six hours is considered optimal for creating new bone, and that a more acute correction impairs medullary blood supply, and inhibits osteogenesis. ${ }^{11,21-24}$ In this study, we employed slower distraction rates. Initially, a rate of approximately $1.0 \mathrm{~mm}$ every 36 hours $(0.25 \mathrm{~mm}$ every nine hours) was used. Later this was reduced to $1.0 \mathrm{~mm}$ every 48 hours $(0.25 \mathrm{~mm}$ every 12 hours) when the length of the regenerated bone reached $6.0 \mathrm{~cm}$. This rate produced satisfactory new bone formation in the distraction gap. Because the two groups of patients are not well matched, it is difficult to compare the present technique of callus distraction with other studies. In group A, the mean external fixation index of 41.9 days $/ \mathrm{cm}$ is comparable with that of others using a distraction rate of $1 \mathrm{~mm} / 24 \mathrm{hrs}$, which ranges between 31 days/cm and 52 days/cm..$^{8,11,25-28}$ In group B, the mean external fixation index of 18.6 days/cm is comparable with that of others using a distraction rate of $1 \mathrm{~mm} / 24 \mathrm{hrs}$, which ranges from 12.2 days $/ \mathrm{cm}$ to 19.7 days $/ \mathrm{cm}^{13,15}$

In October 2001, we started to use callus distraction over an intramedullary nail. Between October 2001 and January 2004, 17 patients attended our hospital for treatment and 14 were treated by lengthening over an intramedullary nail. We followed the indication suggested by Shepherd et $\mathrm{al}^{29}$ that if the area to be lengthened exceeds $5 \mathrm{~cm}$ to $6 \mathrm{~cm}$, the combination of an external fixator and an intramedullary nail should be used. However, a nail was not used in three cases because these patients could not afford the extra cost.

Deep infection occurred in one patient in group B despite following the recommendations of Paley et al. ${ }^{15}$ The rate of deep infection of one in 14 patients was lower than that reported by Simpson et $\mathrm{al}^{10}$ but higher than that of Paley et al. ${ }^{15}$ The patient with a deep infection had received xenodemineralised bone graft and was in a poor nutritional state. Excluding pin-track infection, the rate of complications in group A was higher than in group B, which differs from the results of Paley et al. ${ }^{15}$ In this series, the majority of complications, such as pin loosening or pulling out, were associated with osteoporosis and restriction of knee movement. The use of an intramedullary nail was an advantage in regaining knee motion.

Previous studies have emphasised the importance of preserving the bone marrow and endosteal blood supply in dis- 
traction osteogenesis. ${ }^{3,30-32}$ Several authors have expressed concern that intramedullary nailing may compromise the endosteal blood supply of the diaphyseal bone, ${ }^{10,32-34}$ which affects the quality of the regenerated bone during leglengthening procedures. However, in a rabbit tibial model, Kojimoto et $\mathrm{al}^{7}$ showed that the endosteum and bone marrow are not crucial for adequate callus formation and that periosteum is of particular importance. Clinically, Delloye et $\mathrm{al}^{35}$ found no difference between corticotomy and osteotomy with regard to bone healing and new bone formation. There is evidence to suggest that the periosteal blood supply increases after intramedullary nailing. ${ }^{7,36,37}$ Simpson et al ${ }^{10}$ reported successful lengthening over an intramedullary nail without compromising the quality of the regenerated bone. In our study, callus distraction over an intramedullary nail did not compromise the quality or quantity of the regenerated bone and allowed early removal of the external fixator.

Bone resorption was noted at the docking site during lengthening which could increase the amount of lengthening required. This may have been a result of the chronic osteomyelitis or lack of the normal stresses on the bone. We also noted bone regeneration occurring in the non-contact area at the docking site (Figs 3 and 4).

Progressive shortening of the affected limb occurs with growth in these patients. We used the multiplier method described by Paley et $\mathrm{al}^{38}$ to calculate the overall leg-lengthening required. This method was originally described for predicting the leg-lengthening required in patients with achondroplasia. Our results indicate that it can also be used to predict the lengthening needed in patients with nonunion associated with bone loss due to osteomyelitis.

No benefits in any form have been received or will be received from a commercial party related directly or indirectly to the subject of this article.

\section{Supplementary Material}

$\because$ Supplementary tables showing details of patients, functional results and complications are available with the electronic version of this article on our website at www.jbjs.org.uk

\section{References}

1. Canale ST. Campbell's operative orthopaedics. Vol. 3. Ninth ed. Singapore: Harcourt Asia Mosby, 2001.

2. Tsuchiya H, Tomita K. Distraction osteogenesis for treatment of bone loss in the lower extremity. J Orthop Sci 2003;8:116-24.

3. De Bastiani G, Aldegheri R, Renzi-Brivio L, Trivella G. Limb lengthening by callus distraction (callotasis). J Pediatr Orthop 1987;7:129-34.

4. Trivella GP, Brigadoi F, Aldegheri R. Leg lengthening in Turner dwarfism. J Bone Joint Surg [Br] 1996;78-B:290-3.

5. Keating JF, Simpson AH, Robinson CM. The management of fractures with bone loss J Bone Joint Surg [Br]2005;87-B:142-50.

6. Kabata T, Tsuchiya H, Sakurakichi K, et al. Reconstruction with distraction osteogenesis for juxta-articular nonunions with bone loss. J Trauma 2005;58:1213-22.

7. Kojimoto H, Yasui N, Goto T, Matsuda S, Shimomura Y. Bone lengthening in rabbits by callus distraction: the role of periosteum and endosteum. J Bone Joint Surg $[\mathrm{Br}]$ 1988;70-B:543-9

8. Price CT, Cole JD. Limb lengthening by callotasis for children and adolescents: early experience. Clin Orthop 1990;250:105-11.
9. Kucukkaya M, Kabukcuoglu Y, Tezer M, Kuzgun U. Management of childhood chronic tibial osteomyelitis with the llizarov method. J Pediatr Orthop 2002;22:632-7.

10. Simpson AH, Cole AS, Kenwright J. Leg lengthening over an intramedullary nail. J Bone Joint Surg [Br] 1999;81-B:1041-5.

11. Sangkaew C. Distraction osteogenesis for the treatment of post traumatic complications using a conventional external fixator: a novel technique. Injury 2005;36:18593.

12. Saleh M, Rees A. Bifocal surgery for deformity and bone loss after lower-limb fractures: comparison of bone-transport and compression-distraction methods. J Bone Joint Surg [Br] 1995;77-B:429-34.

13. Kocaoglu M, Eralp L, Rashid HU, Sen C, Bilsel K. Reconstruction of segmental bone defects due to chronic osteomyelitis with use of an external fixator and an intramedullary nail. J Bone Joint Surg [Am] 2006;88-A:2137-45.

14. Paley D, Catagni MA, Argnani F, et al. llizarov treatment of tibial nonunions with bone loss. Clin Orthop 1989;241:146-65.

15. Paley D, Herzenberg JE, Paremain G, Bhave A. Femoral lengthening over an intramedullary nail: a matched-case comparison with llizarov femoral lengthening. J Bone Joint Surg [Am] 1997;79-A:1464-80

16. Paley D. Problems, obstacles, and complications of limb lengthening by the llizarov technique. Clin Orthop 1990:250:81-104

17. Jain AK, Sinha S. Infected nonunion of the long bones. Clin Orthop 2005;431:57-65.

18. Catagni MA, Lovisetti L, Guerreschi F, Combi A, Ottaviani G. Cosmetic bilateral leg lengthening: experience of 54 cases. J Bone Joint Surg [Br] 2005;87-B:1402-5.

19. Xu J, Li Q, Yang L, et al. Treatment of complex bone nonunion with external skeletal fixation. Zhonghua Wai Ke Za Zhi 2002:40:280-3 (in Chinese).

20. Minematsu K, Tsuchiya H, Taki J, Tomita K. Blood flow measurement during dis traction osteogenesis. Clin Orthop 1998;347:229-35.

21. Ilizarov GA. The tension-stress effect on the genesis and growth of tissues. Part II: the influence of the rate and frequency of distraction. Clin Orthop 1989;239:263-85.

22. Fink B, Krieger M, Strauss JM, et al. Osteogenesis and its influencing factors during treatment with the llizarov method. Clin Orthop 1996;323:261-72.

23. Ilizarov GA. Clinical application of the tension-stress effect for limb lengthening. Clin Orthop 1990;250:8-26.

24. Ilizarov GA. Transosseous osteosynthesis: theoretical and clinical aspects of the regeneration and growth of tissue. Berlin: Springer-Verlag, 1992:137-278.

25. Sangkaew C. Distraction osteogenesis with conventional external fixator for tibial bone loss. Int Orthop 2004;28:171-5.

26. Aldegheri R, Renzi-Brivio L, Agostini S. The callotasis method of limb lengthening. Clin Orthop 1989;241:137-45.

27. Kristiansen LP, Steen H. Reduced lengthening index by use of bifocal osteotomy in the tibia: comparison of monofocal and bifocal procedures with the llizarov external fixator. Acta Orthop Scand 2002;73:93-7.

28. Yasui N, Kojimoto H, Sasaki K, et al. Factors affecting callus distraction in limb lengthening. Clin Orthop 1993;293:55-60.

29. Shepherd LE, Zalavras CG, Shean C. Femoral lengthening techniques. Operative Techniques in Orthopaedics 2001;11:178-86.

30. Dal Monte A, Donzelli 0. Tibial lengthening according to llizarov in congenital hypoplasia of the leg. J Pediatr Orthop 1987;7:135-8.

31. Kawamura B, Hosono S, Takahashi T, et al. Limb lengthening by means of subcutaneous osteotomy: experimental and clinical studies. J Bone Joint Surg [Am] 1968;50-A:851-78.

32. Klein MP, Rahn BA, Frigg R, Kessler S, Perren SM. Reaming versus non-reaming in medullary nailing: interference with cortical circulation of the canine tibia. Arch Orthop Trauma Surg 1990;109:314-16.

33. Reichert IL, McCarthy ID, Hughes SP. The acute vascular response to intramedullary reaming: microsphere estimation of blood flow in the intact ovine tibia. J Bone Joint Surg [Br] 1995;77-B:490-3.

34. Sitter T, Wilson J, Browner B. The effect of reamed versus unreamed nailing on intramedullary blood supply and cortical viability. J Orthop Trauma 1990;4:232

35. Delloye C, Delefortrie G, Coutelier L, Vincent A. Bone regenerate formation in cortical bone during distraction lengthening: an experimental study. Clin Orthop 1990;250:34-42.

36. Silberg ET, Goulet JA, Greenfield ML. Femoral lengthening: conventional Ilizarov technique compared to lengthening over an intramedullary rod. Orthop Trans 1997;21:71.

37. Trueta J. The role of the vessels in osteogenesis. J Bone Joint Surg [Br] 1963;45 B:402-18.

38. Paley D, Matz AL, Kurland DB, Lamm M, Herzenberg JE. Multiplier method for prediction of adult height in patients with achondroplasia. J Pediatr Orthop 2005;25:539-42. 